\title{
Seepage Investigation on an Existing Dam Using Very Low Frequency Electromagnetic (VLF-EM) Methods: A Case Study of Shagari Earth Dam, Sokoto, North Western Nigeria
}

\author{
U. Z. Magawata1', D. S. Bonde1, B. U. Abdullahi', Basiru Qudus², M. N. Yahaya³ \\ ${ }^{1}$ Physics Department, Kebbi State University of Science and Technology, Aliero, Nigeria \\ ${ }^{2}$ Department of Science Laboratory Technology, The Oke-Ogun Polytechnic, Saki, Oyo State, Nigeria \\ ${ }^{3}$ Department of Physics with Electronics, Federal University Birnin-Kebbi, Birnin Kebbi, Nigeria \\ Email: uzayyanu@yahoo.com
}

How to cite this paper: Magawata, U.Z., Bonde, D.S., Abdullahi, B.U., Qudus, B. and Yahaya, M.N. (2020) Seepage Investigation on an Existing Dam Using Very Low Frequency Electromagnetic (VLF-EM) Methods: A Case Study of Shagari Earth Dam, Sokoto, North Western Nigeria. International Journal of Geosciences, 11, 25-36.

https://doi.org/10.4236/ijg.2020.112003

Received: August 21, 2019

Accepted: February 14, 2020

Published: February 17, 2020

Copyright $\odot 2020$ by author(s) and Scientific Research Publishing Inc. This work is licensed under the Creative Commons Attribution International License (CC BY 4.0).

http://creativecommons.org/licenses/by/4.0/

\section{(c) (i) Open Access}

\begin{abstract}
Very low frequency (VLF-EM) was used to assess variations in overburden composition, bedrock lithology and the hidden Sedimentary structures within the foundation of Shagari Dam of the sedimentary basin of Northwestern Nigeria. Four VLF-electromagnetic (EM) traverses were occupied at $10 \mathrm{~m}$ intervals. The VLF normal and filtered real component irregularities identify major geological interfaces suspected to be faults/fractured zones. The points of crossover between the real and imaginary components delineate the fractured zones, which were identified as areas of possible seepage (sloughing and piping). The fractured zones are suspected to be present at all traverses. In total, 38 fractured zones were identified along the dam embankment and canal site, while 17 major fractures occurrence dippers along the Traverses at a point, Traverse $1\left(\mathrm{~F}_{3}, \mathrm{~F}_{4}, \mathrm{~F}_{5}, \mathrm{~F}_{7}, \mathrm{~F}_{10}, \mathrm{~F}_{11}\right)$, Traverse $2\left(\mathrm{~F}_{12}, \mathrm{~F}_{13}, \mathrm{~F}_{21}, \mathrm{~F}_{22}\right)$, Traverse $3\left(\mathrm{~F}_{23}, \mathrm{~F}_{24}, \mathrm{~F}_{29}\right)$ and Traverse $4\left(\mathrm{~F}_{32}, \mathrm{~F}_{33}, \mathrm{~F}_{34}, \mathrm{~F}_{38}\right)$, and coincide with cross over point at 4 traverses. These seepage zones cause heterogeneity in the subsurface structure that could be prime to dam failure which in turn leads to the flooding, decreases in irrigations activities of the peoples leaving around the dam and loss of several hundreds of life when care not taken. The result of the study suggests that VLF is suitable for observing seepages in embankment dams.
\end{abstract}

\section{Keywords}

Overburden, Interfaces, Occurrence, Heterogeneity, Embankment 


\section{Introduction}

The dam falls between latitudes $12^{\circ} 4357^{\prime} 5^{\prime \prime} \mathrm{N}$ and $12^{\circ} 7326^{\prime} 30^{\prime \prime} \mathrm{N}$, Longitudes $5^{\circ} 07^{\prime} 070^{\prime \prime E}$ and $5^{\circ} 118^{\prime \prime} 615^{\prime \prime E}$. It is located southeast of Sokoto city (Figure 1). Dams are among the largest and most important projects in civil engineering [1]. For geologic, hydrologic and topographic reasons, there are limited numbers of ideal sites for dam It is therefore very important to carry out geotechnical and geophysical investigations on any proposed dam site. The information provided by the study is expected to aid dam site investigation, dams mainly intended for water supplies require a low tolerance of seepage losses. Besides, the design of dam structures must be adapted to the existing site conditions [2], to minimize the losses. Failure to do any of these may invariably result in unplanned seepage and/or total collapse of the structure. [3] Examined causes of dam failures worldwide and discovered that $25 \%$ of the failures were due to geotechnical problems associated with seep-age, inadequate seepage cut-off, faults, settlements and land-slides.

Seepage through a dam is a slow discharge or escape of liquid that is supposed to be retained in the reservoir, through conduits (fracture/fault lines) to the flank of the dam. It reduces the expected quantity of water, weaken dam construction and damage dam gates [4]. Certain soil can swell if they get saturated with the seeping water and when there is loss of water in them, they shrink drastically. These expansions and shrinkages of soils can result in cracks and collapse of the dam. Seepage is one of the major reasons for embankment dam failures and may constitute a significant potential social dislocation (displacement of people, loss of valuable life and properties) if not examined. Cost of reconstruction of a failed dam can be worrisome and shortage of water supply may hinder the objective of dam construction. The purposes of this study is to identify and describe structural defects such as faults, joints, solution channels in the rocks, to determine

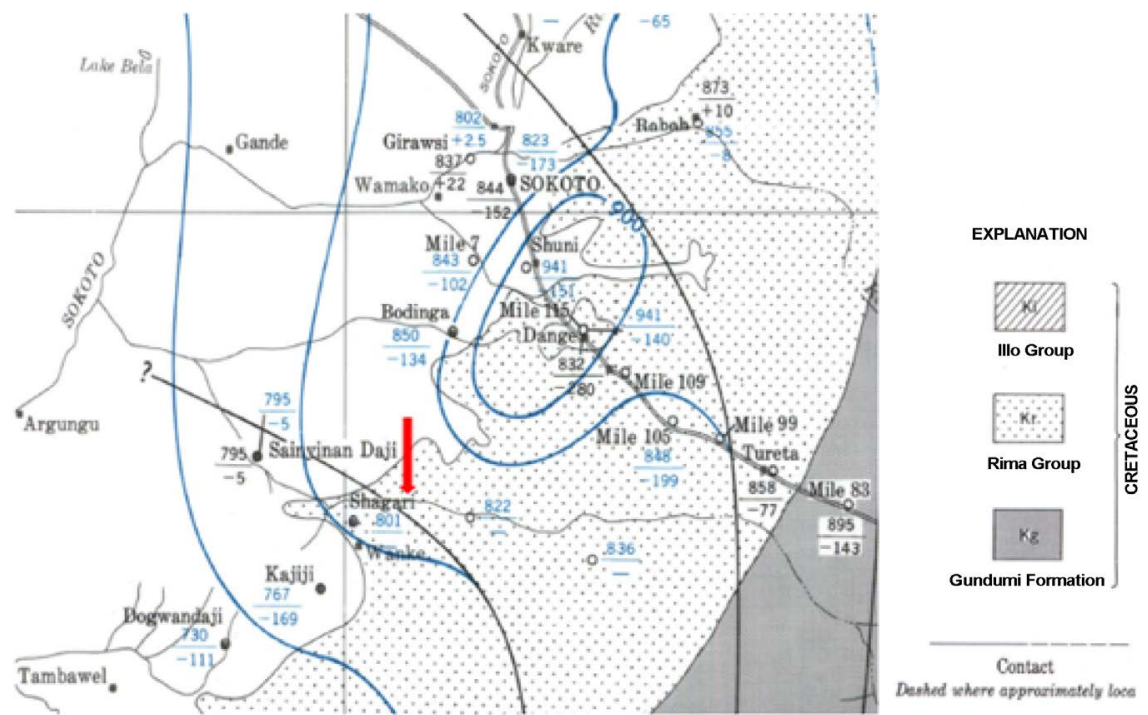

Figure 1. Location of the study area [11]. 
and characterize the depth of groundwater, and evaluation of possible present seepage paths; resulting from fracturing or dissolution of the bedrock and its adverse effect on the dam embankment, this will provide information about subsurface geologic structures that may control subsurface flow and seepage, since geophysical methods have the potential of detecting internal erosion and anomalous seepage at an early stage before the safety and integrity of the dam is at palisade.

\section{Description of the Study Area}

\subsection{Location}

The place described its origin in his book titled "Beckoned to serve". He mentioned that Dan Fodio reportedly said "you can remain and sha (enjoy) your gari (millet flour)"; it is a valley located in Shagari Local Government Area, Nigeria [5]. The dam falls between latitudes $12^{\circ} 4357^{\prime} 5^{\prime \prime} \mathrm{N}$ and $12^{\circ} 7326^{\prime} 30^{\prime \prime} \mathrm{N}$, Longitudes $5^{\circ} 07^{\prime} 070^{\prime E}$ and $5^{\circ} 118^{\prime \prime} 615^{\prime E}$. It is located south east of Sokoto city. Shagari falls into the typically tropical climate which has distinct wet and dry season. The study area itself is situated in the arid and Semi-arid areas of Northern Nigeria [6] (Figure 1). The climate of the study area is tropical continental and is dominated by two opposing air masses, the dry tropical continental blowing from the Sahara Desert and moist Tropical maritime blowing from the North Easterly direction, the later comes from South-Westerly direction [7]. These two major air masses result in two major seasons, the wet and dry season. While the rainy season commences from mid-April and lasts to the end of September, the dry season extends from early October to May. The Harmattan period is characterized by a dry, cold and dusty wind experienced in the state between November and February. During this period, the weather is usually cold at night and in the morning with temperature often dropping to less than $200^{\circ} \mathrm{C}$ in some cases [7]. Temperatures are highest from late March to May, ranging from $350^{\circ} \mathrm{C}$ to $450^{\circ} \mathrm{C}$. Mean annual rainfall is about $600 \mathrm{~mm}$ with most of it falling in July and August. Over the last fifty years, the rainy season has been characterized by late arrivals of rains, long spells of aridity of up to 21 days and early cessations; this is a suggestive of climate change [8].

\subsection{Geology of the Area}

The Rima Group (Figure 1), consists of a marine transgressive series of fine-grained sand and friable sandstone, mudstone, and some marly limestone and shale. North of the River Sokoto in the northern part of the Sokoto Basin, the group is divided into three formations, the Taloka at the base, the Dukamaje in the middle, and the Wurno at the top [9]. The Taloka Formation, where exposed in the northern part of the Sokoto Basin, attains a thickness of 400 feet and consists of white fine-grained friable sandstone containing some thin intercalated beds of carbonaceous mudstone or shale [10]. The Dukamaje Formation, between the Taloka and the Wurno, crops out only north of the River Rima. Originally named the "Mososaurus Shales", it consists at Dukamaji of 70 feet of shale, thin limes- 
tone, and mudstone, and some gypsum and an assemblage of invertebrate and vertebrate fossils at the base. The uppermost formation of the Rima Group, the Wurno, consists of 75 feet of pale fine sand and some silt. According to [9], the Dukamaje Formation has not been found south of Rabah on the River Sokoto, and hence south of this point the Wurno and the T'aloka are mapped together as a unit. In the northern part of the Sokoto Basin, samples fron 1 boreholes closely resemble those taken from surface outcrops of the Rima Group. Thick beds of well-sorted fine white sand and dark gray lignitic clay containing iron sulfide (pyrite) are found in boreholes near Sokoto and also at Rabah and Wurno. Individual beds may exceed several hundred feet in thickness and grade laterally from clay to fine sand within short distances. Coarse sand in thin beds occurs near the base of the Taloka Formation at Wurno, Dange, and Sokoto. Toward the southern part of the Sokoto Basin, the Wurno Taloka lithology departs once again from the typical fine-grained lithology observed in outcrop. Clay beds become less abundant than sandy beds, and the sand changes from the characteristic fine texture of the north to medium and coarse texture in the South. The total thickness of the Rima Group ranges from zero at the eastern limit of its outcrop to more than 1000 feet in it's down dip extensions near the Niger frontier. The regional dip of the Rima near Sokoto is about 20 feet per mile.

\section{Material and Method}

\subsection{Very Low Frequency Electromagnetic (VLF-EM) Technique}

The instrument used for the VLF profiling is the ABEM WADI, the dam profile cover a $2.9 \mathrm{~km}, 4$ transverses with total of 2900 VLF stations were established in all. The reading was taken at an interval of $10 \mathrm{~m}$. VLF-EM is an inductive exploration technique that is suitable for mapping shallow subsurface structural features in which the primary EM waves induces current flow, [12]. Although both the real and quadrature components of the VLF-EM were measured, the real component data which are usually more diagnostic of linear features [13], were processed for qualitative interpretation. The VLF data that is, real and filtered real components of the EM fields measured was subjected to Fraser filtering techniques to increase the signal to noise ratio of the data set and enhance the anomaly signature. Using the [14], techniques, the raw real and filtered real components were plotted against station positions. A 2D inversion of real component data was also carried out using the same software.

\subsection{VLF-EM Survey}

VLF surveys may be run on airborne or ground platforms. GEM's GSM-90 AV is an example of an airborne version and the GSM-19 V and GSM-19 TV are GEM's ground versions. The airborne version is equipped with two sensors so it can be tuned to two VLF transmitting stations concurrently. The ground version is new and is called walking VLF. With this system, you can use it either with a magnetometer or standalone (two VLF receivers). Using the walking version, it is possible to survey $10 \mathrm{~km}$ or more of profile a day. GEM's VLF systems meas- 
ure a variety of parameters, including horizontal component (x) i.e. in-phase as a percentage of the total field. The component is so called because its nature is that it is in phase with the incoming primary signal; vertical component (y) i.e. out-of-phase/quadrature as a percentage of the total field. This is so called, also, because the component is $90^{\circ}$ to the primary signal; and field strength in Pico-Tesla [15]. This is a powerful combination of parameters designed to maximize the effectiveness of VLF survey. GEM has also made advanced technological innovations in its software and hardware-giving easy-to-use interface increase accuracy. The development of a chip-based tilt sensor to replace commonly used a fluid-filled sensor which means that the detector can operate much faster.

\subsection{Filtering Procedures}

The measured dip angle response needs to be filtered to reduce the random noise and long spatial wavelengths. However, for practical purposes it is not generally necessary to eliminate the noise, and long spatial wavelength as VLF ensures fairly accurate measurements with random errors well below an appreciable level. To overcome some of these problems [16], devised a simple numerical filter, which converts crossovers of current polarity into peaks by differencing successive values of tilt angle (the in phase component) along the profile. The Fraser filter shifts the measured dip angle data by $90^{\circ}$. Thus, the Fraser filtering transforms the anomaly such that parts with maximum slope will appear as maximum amplitude. In a sequence of consecutive readings of tilt angle, say $Q_{1}, Q_{2}, Q_{3}$ and $Q_{4}$; the term $\left(Q_{2}-Q_{1}\right)$ not only shifts the dip angle but also attenuates the spatial wavelengths.

Numerically averaging weighted values of the adjacent sets of such differences i.e. $\left(\mathrm{Q}_{2}-\mathrm{Q}_{1}\right) / 4+\left(\mathrm{Q}_{3}-\mathrm{Q}_{2}\right) / 2+\left(\mathrm{Q}_{4}-\mathrm{Q}_{3}\right) / 4$ which reduces to $\left(\mathrm{Q}_{3}+\mathrm{Q}_{4}\right)-\left(\mathrm{Q}_{1}+\right.$ $\mathrm{Q}_{2}$ ) reduces noise. [16] used linear filtering for the analysis of VLF dip angle data in an extension of the Fraser filter. They describe the magnetic field arising from a subsurface $2 \mathrm{D}$ current distribution assumed in a horizontal sheet of varying current density situated everywhere at a depth equal to the distance between the measurement stations.

\subsection{VLF-EM Data Processing}

VLF field data were filtered using Fraser Filtering method. [17] Suggested a simple numerical technique aimed at eliminating erroneous interpretation of very low frequency (VLF) data caused by large geological noise component generated from the transmitted frequency. According to [17], this filtering method improves the resolution of the anomalies and eases their recognition.

\subsection{VLF Data Acquisitions}

On the field, a total of 2900 VLF stations were established following these procedures:

- An ABEM WADI was used for the acquisition of data; 
- The ABEM WADI operate at a frequency of 15.0 and $15.1 \mathrm{kHz}$;

- Data were acquired along the 4 traverses; inter station space in $10 \mathrm{~m}$;

- The orientation of the traverses is $\mathrm{S}-\mathrm{N}$ on the global coordinate;

- The length of each of the first 2 traverses is $850 \mathrm{~m}$, while the remaining 2 traverses were $600 \mathrm{~m}$ each.

\section{Result and Discussion}

\subsection{VLF-EM Profile Presentation}

The anomaly curves generated from the filtered component of the VLF-EM response enabled qualitative identification of linear features and possible depth of occurrences. These features (geological interface/fault zones) are delineated as positive peaks of the real component anomalies with the sharp and broad peaks indicating depth of conductive zones [18].

Interpretation is done by considering the high-amplitude signals, which is diagnostic of weathered or fractured zones. The double plots of the filtered real and filtered imaginary components enable qualitative identification of the top of linear features, i.e. points of coincidence of crossovers and positive peaks of the real and filtered anomalies. Profiles 1 - 4 show the VLF-EM anomaly along $\mathrm{KH}$ Contour Section (Figure 2(b)-Figure 5(b)). The linear features with positive filtered real amplitude (high) in all the profiles show areas with conductivity. The visual inspection of these anomaly curves enabled the qualitative identification of the top of linear topographies as points of coincidence of crossover and positive peaks of the real and filtered real anomaly curves.

\subsection{Interpretation of VLF-EM Sections}

\subsubsection{Traverse 1}

In Figure 2(a), fracture zones were located at station some positions, the fracture zones identified as $\left(\mathrm{F}_{1}-\mathrm{F}_{11}\right)$, with some identified fracture $\mathrm{F}_{1}, \mathrm{~F}_{2}, \mathrm{~F}_{6}, \mathrm{~F}_{8}$ and $\mathrm{F}_{9}$ at station positions are the shallowest zone, while conductors (fracture zone) at $\mathrm{F}_{3}, \mathrm{~F}_{4}, \mathrm{~F}_{5}, \mathrm{~F}_{7}, \mathrm{~F}_{10}$, and $\mathrm{F}_{11}$ appear to be the deepest extended beyond $30 \mathrm{~m}$, with an amplitude of $-40 \%$ signal responses. In Traverse 1 , it can be deduced that eleven fractured zones were delineated, among which six fractured zones $\left(\mathrm{F}_{3}, \mathrm{~F}_{4}\right.$, $\mathrm{F}_{5}, \mathrm{~F}_{7}, \mathrm{~F}_{10}$, and $\mathrm{F}_{11}$ ) show a deep trend of the conductors. These negative peaks, mapped as fractures on the filtered real component, are zones of interest for groundwater perception in the sediment terrain. The asymmetry of these conductive anomalies suggests that the conductive structures are dipping, therefore the anomaly patterns exhibit varying amplitudes and are said to be controlled by the depth of the body to the surface and the attitude of the area. The VLF-EM raw real data were converted to the pseudo-section using the K-H filter. Pictorial scrutiny of this section allows the determination of depth of occurrence, width and dip of the body. From (Figure 2(b)), the attitude of the body, the length of fractures and the depth to top and bottom of the fractures can be determined. The presence of cross-cutting fractures can be identified, and the widths of the 


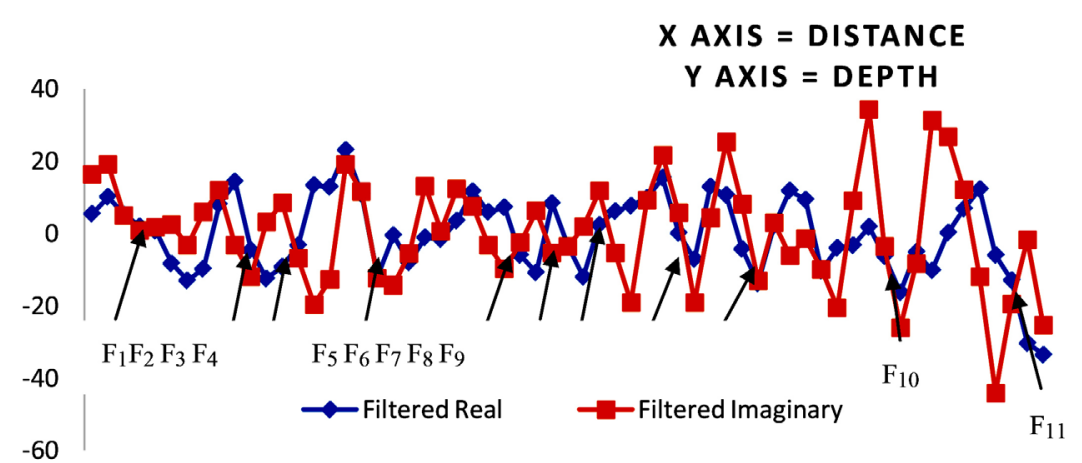

(a)
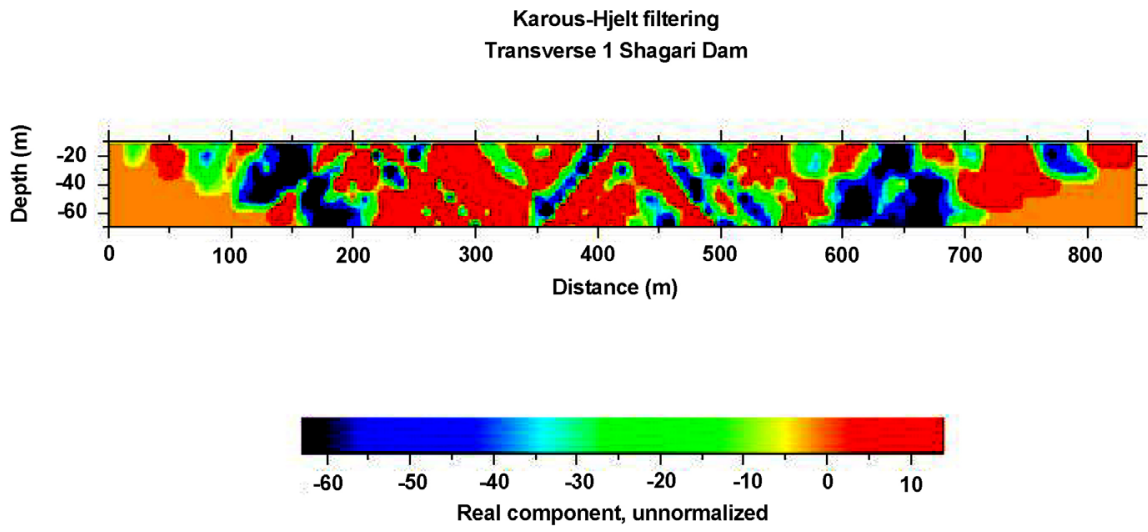

(b)

Figure 2. (a) VLF-EM Profile along Traverse 1; (b) Pseudo-Section of the inverted VLF-EM real component along Traverse 1.

fractures are moderately thick. (Figure 2(b)) shows the corresponding K-H pseudo-section of Profile 1. Different features of varying degrees of conductivity trending in different directions were delineated on the section, and are said to be coincide with crossover (Figure 2(a)) with their corresponding depth and station number, with major fracture identified are extended beyond a depth of 30 $\mathrm{m}$ as shown in the Pseudo section (Figure 2(b)), indicating a highly conductive body. These zones are considered to be highly conductive and therefore can act as leakage zones.

\subsubsection{Traverse 2}

In Figure 3(a), fracture zones were located at station some positions, the fracture zones identified as $\left(\mathrm{F}_{12}-\mathrm{F}_{22}\right)$, with some identified fracture $\mathrm{F}_{14}, \mathrm{~F}_{15}, \mathrm{~F}_{16}, \mathrm{~F}_{17}$, $\mathrm{F}_{18}, \mathrm{~F}_{19}$ and $\mathrm{F}_{20}$ at station positions are the shallowest zone, while conductors (fracture zone) at $\mathrm{F}_{12}, \mathrm{~F}_{13}, \mathrm{~F}_{21}$, and $\mathrm{F}_{22}$ appear to be the deepest extended beyond $40 \mathrm{~m}$, with an amplitude of $30 \%-50 \%$ signal responses. As shown in the traverse 2 it can be deduced that eleven fractured zones were delineated, among which four fractured zones $\left(\mathrm{F}_{12}, \mathrm{~F}_{13}, \mathrm{~F}_{21}\right.$, and $\left.\mathrm{F}_{22}\right)$ show a deep trend of the conductors. These negative peaks, mapped as fractures on the filtered real component, are 


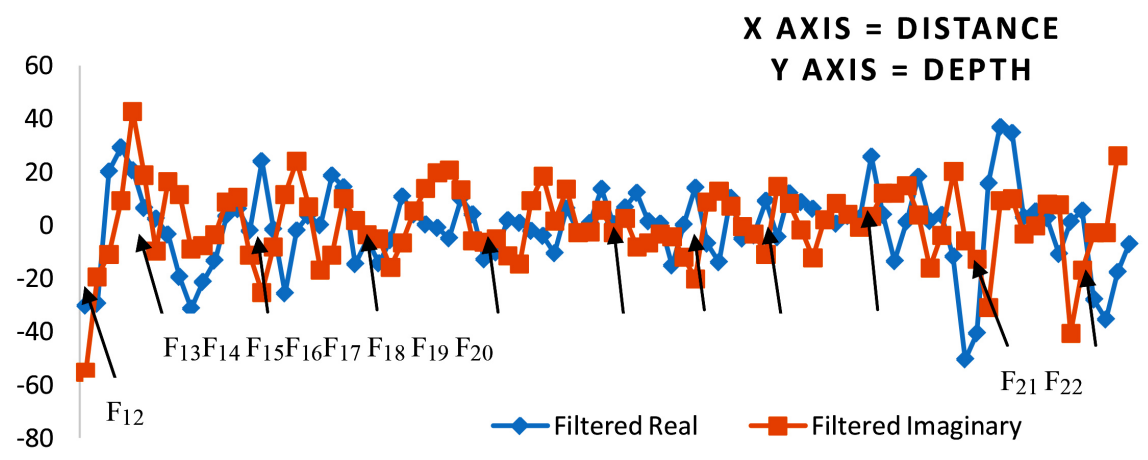

(a)
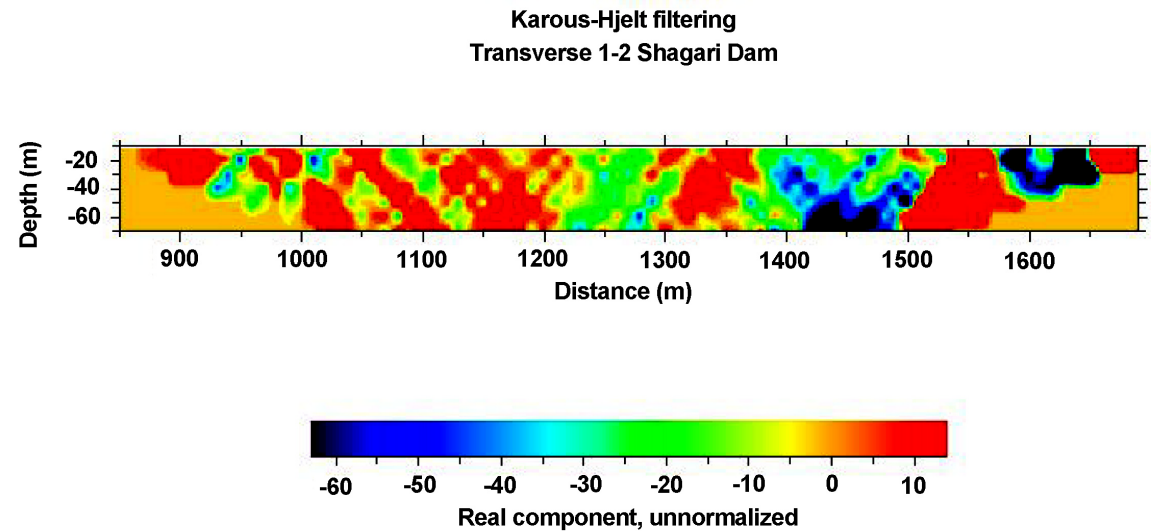

(b)

Figure 3. (a) VLF-EM Profile along Traverse 2; (b) Pseudo-Section of the inverted VLF-EM real component along Traverse 2.

zones of interest for groundwater perception in the sediment terrain. Diverse features of conductivity fluctuating in different directions were delineated that coincide with crossover (Figure 3(a)) with their corresponding depth, major fracture identified are extended beyond a depth of $40 \mathrm{~m}$ as shown in the $\mathrm{KH}$ Pseudo section (Figure 3(b)), indicating a highly conductive body at subsurface that are probable seepage zones.

\subsubsection{Traverse 3}

In Figure 4(a) as shown in the traverse 3 it can be deduced that seven fractured zones were delineated, among which three fractured zones were located at station some positions, the fracture zones identified as $\left(\mathrm{F}_{23}-\mathrm{F}_{29}\right)$, with some identified fracture $\mathrm{F}_{25}, \mathrm{~F}_{26}, \mathrm{~F}_{27}$, and $\mathrm{F}_{28}$ at station positions are the shallowest zone, while conductors (fracture zone) at $\mathrm{F}_{23}, \mathrm{~F}_{24}$, and $\mathrm{F}_{29}$ show abnormal feature with an amplitude of $10 \%-20 \%$ signal responses. Diverse features of conductivity fluctuating in different directions were delineated that coincide with crossover (Figure 4(a)) with their corresponding depth, major fracture identified are extended beyond a depth of $40 \mathrm{~m}$ as shown in the $\mathrm{KH}$ Pseudo section (Figure 4(b)), indicating a highly conductive body at subsurface that are probable seepage zones. 


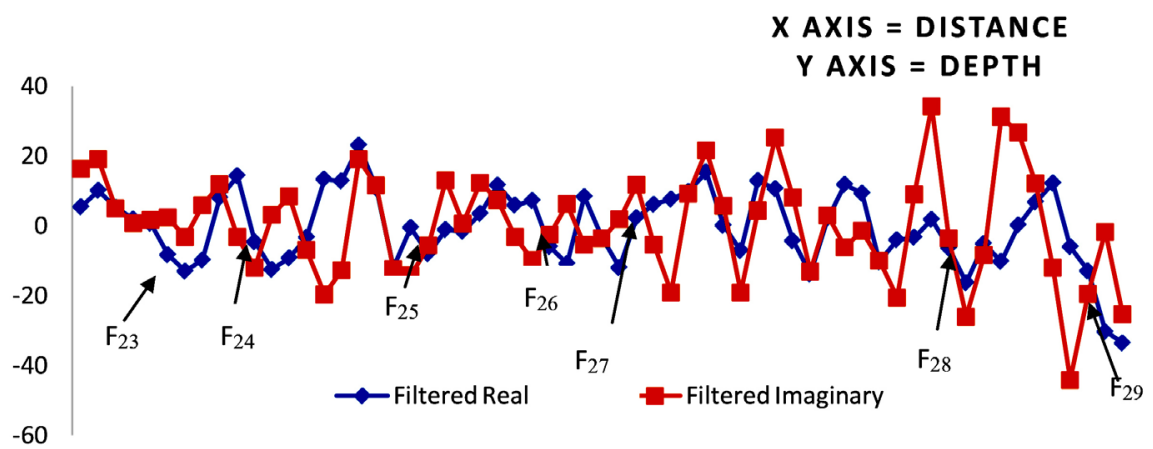

(a)

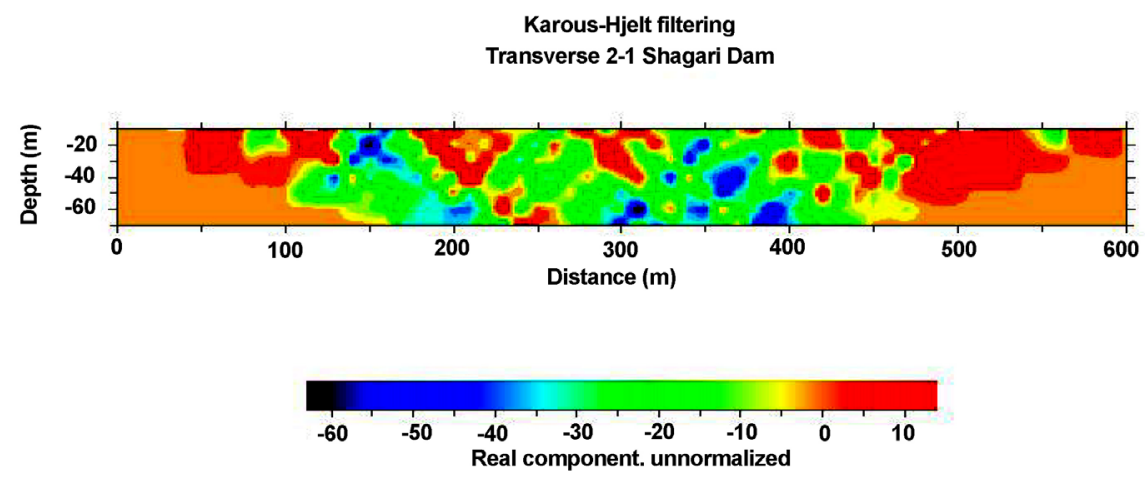

(b)

Figure 4. (a) VLF-EM Profile along Traverse 3; (b) Pseudo-Section of the inverted VLF-EM real component along Traverse 3.

\subsubsection{Traverse 4}

In (Figure 5(a)) as shown in the traverse 3 it can be deduced that seven fractured zones were delineated, among which three fractured zones were located at station some positions, the fracture zones identified as $\left(\mathrm{F}_{30}-\mathrm{F}_{38}\right)$, with some identified fracture $\mathrm{F}_{30}, \mathrm{~F}_{31}, \mathrm{~F}_{35}, \mathrm{~F}_{36}$, and $\mathrm{F}_{37}$ at station positions are the shallowest zone, while conductors (fracture zone) at $\mathrm{F}_{32}, \mathrm{~F}_{33}, \mathrm{~F}_{34}$, and $\mathrm{F}_{38}$ show abnormal feature with an amplitude of $25 \%$ - $40 \%$ signal responses. Other features identified with varying degree of conductivity appear in different directions that coincide with crossover (Figure 5(a)) with their corresponding depth, major fracture identified are extended beyond a depth of $60 \mathrm{~m}$ are shown in the KH Pseudo section (Figure 5(b)), indicating a highly conductive body at subsurface that are probable possible seepage zones.

\section{Conclusion}

Geophysical investigation was carried out on Shagari Dam. The VLF-EM data were acquired along four traverses. The VLF data effectively identified relatively wide areas of conductivity by noticing the boundaries of conductive regions. Both the maximum differences and points of crossover between the real and imaginary curves were used to delineate the sheared/fractured and weathered zones, which were identified as areas of fracture and probable areas of internal destruction. 

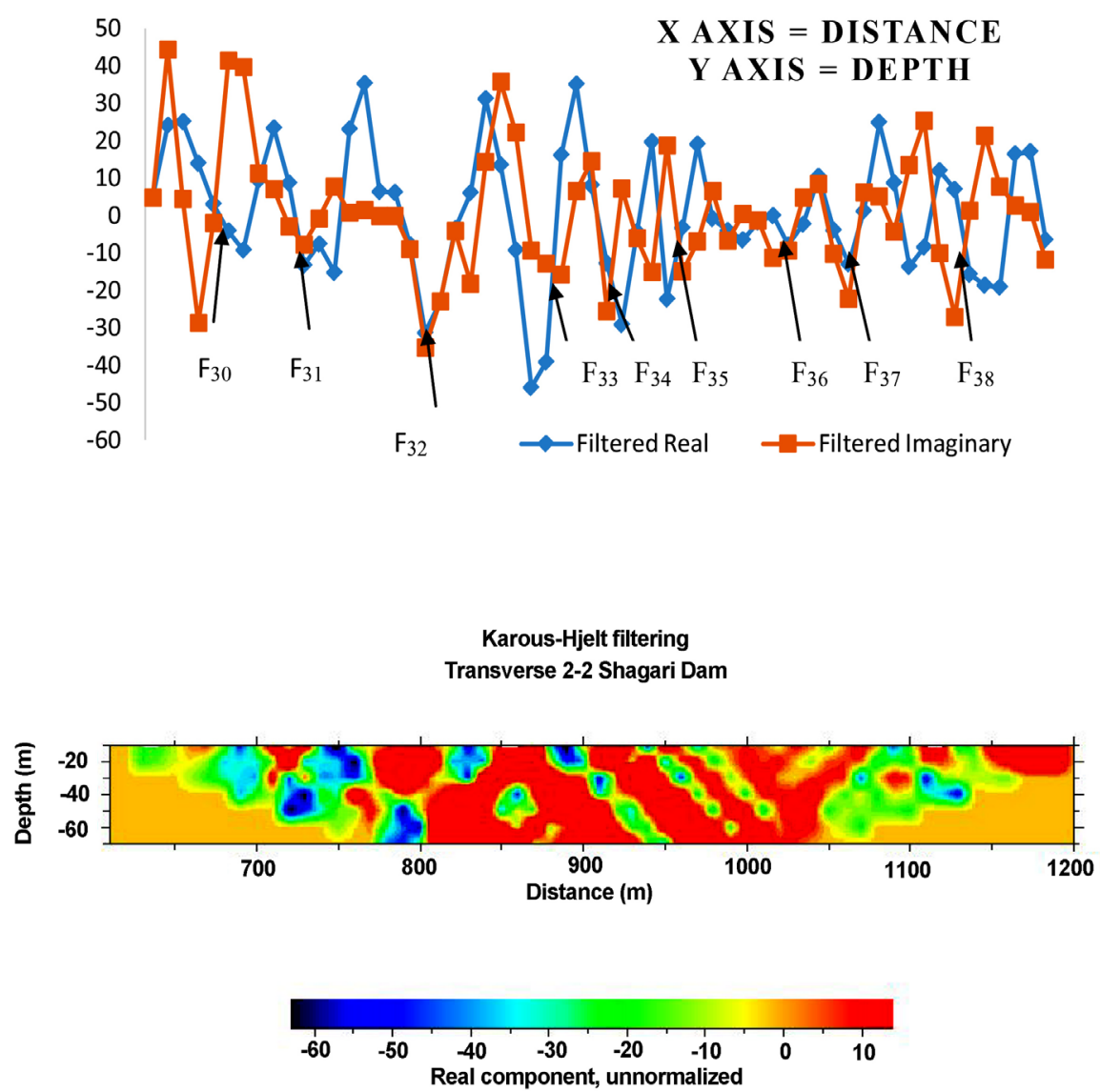

Figure 5. (a) VLF-EM Profile along Traverse 4; (b) Pseudo-Section of the inverted VLF-EM real component along Traverse 4.

The results of the study suggest that the EM VLF method is an adequate method for monitoring seepages in dam embankments. The point of crossover between the real and imaginary components was used to delineate the fractured zones, which were identified as areas of possible leakage. The fractured zones were identified on all four traverses as shown in Figure 2(a) and Figure 5(a), the evidences of fractures are designated as $\mathrm{F}_{1}-\mathrm{F}_{38}$. A total of 38 fractured zones were identified, with the deepest fracture lineament occurring at Traverse $1\left(\mathrm{~F}_{3}\right.$, $\left.\mathrm{F}_{4}, \mathrm{~F}_{5}, \mathrm{~F}_{7}, \mathrm{~F}_{10}, \mathrm{~F}_{11}\right)$, Traverse $2\left(\mathrm{~F}_{12}, \mathrm{~F}_{13}, \mathrm{~F}_{21}, \mathrm{~F}_{22}\right)$, Traverse $3\left(\mathrm{~F}_{23}, \mathrm{~F}_{24}, \mathrm{~F}_{29}\right)$ and Traverse $4\left(\mathrm{~F}_{32}, \mathrm{~F}_{33}, \mathrm{~F}_{34}, \mathrm{~F}_{38}\right)$. The results presented in this study reveal that, Shagari Dam embankment fractured and leakage could occur along porous zones. Such defect could be responsible for dam failure and total collapse.

\section{Recommendation}

We recommend additional detailed characterization of the Shagari Dam, using other complementary geophysical methods such as ground-penetrating radar, 2D and 3D electrical resistivity, Aeromagnetic method and seismic refraction tomography in order to confirm the fracture zones delineated using the EM method and to elucidate the shape of the fractures. 


\section{Conflicts of Interest}

The authors declare no conflicts of interest regarding the publication of this paper.

\section{References}

[1] Coduto, D.P. (1999) Geotechnical Engineering: Principles and Practice. Prentice Hall Inc., Upper Saddle River, NJ.

[2] Ajayi, O., Olorunfemi, M.O., Ojo, J.S., Adegoke-Anthony, C.W., Chikwendu, K.K., Oladapo, M.I., Idornigie, A.I. and Akinluyi, F. (2005) Integrated Geophysical and Geotechnical Investigation of A Dam Site on River Mayo Ini, Adamawa State, Northern Nigeria. Africa Geoscience Review, 12, 179-188.

[3] Biswas, A.K. and Charttergee, S. (1971) Dam Disasters-An Assessment. Engineering Journal (Canada), 54, 3-8.

[4] Olorunfemi, M.O., Ojo, J.S., Sonuga, F., Ajayi, O. and Oladapo, M.I. (2000) Geoelectric and Electromagnetic Investigation of the Failed Koza and Nasarawa Earth Dams around Katsina, Northern Nigeria. Journal of Mining Geology, 36, 51-65.

[5] Shagari, S. (2001) Beckoned to Serve. Heinemann Education Books, Nigeria, 5.

[6] Yelwa, S.A. (2012) An Assessment of Vegetation Cover Change across Northern Nigeria Using Trend Line and Principal Component Analysis. Journal of Agriculture and Environmental Sciences, 1, 1-18.

[7] Davis, G. (1982) Sokoto State in Maps: An Atlas of Physical and Human Resources. University Press Limited, Ibadan, Oyo, Nigeria.

[8] Iliya, M.A. (2013) An Overview of Sokoto State: United Nations Development Programmed. Nigeria Chapter UNDP 2013.

[9] Jones, B. (1948) The Sedimentary Rocks of Sokoto Province. Nigerian Geological Survey Bulletin, 18, 75.

[10] Parker, D.H., Fargher, M.N., Carter, J.D. and Turner, D.C. (1964) Geological Map of Nigeria: Nigeria Geological Survey Series 1: 250,000, Sheet NOS. 1, 2, 3, 6, 7, and 8.

[11] Anderson, H.R. and Ogilbee, W. (1973) Aquifers in the Sokoto Basin, Northwestern Nigeria Northwestern Nigeria, with a Description of the General Hydrogeology of the Region. Contributions to the Hydrology of Africa and the Mediterranean Region Library of Congress Catalog-Card No. 73-600131.

[12] Adelusi, A.O., Adiat, K.A.N. and Amigun, J.O. (2009) Integration of Surface Electrical Prospecting Methods for Fracture Detection in Precambrian Basement Rocks of Iwaraja Area Southwestern Nigeria. Ozean Journal of Applied Sciences, 2, 265-280.

[13] Fraser, D.C. (1989) Contouring of VLF-EM Data. Geophysics, 54, 245-253.

[14] Karous, M.R. and Hjelt, S.E. (1983) Linear Filtering of VLF Dip-Angle Measurements. Geophysical Prospecting, 31, 782-894.

https://doi.org/10.1111/j.1365-2478.1983.tb01085.x

[15] Olatunji, S. (2012) Electromagnetic Characterization of the Fracture System within Older Granite of North Central Nigeria. Science Focus, 17, 222-229.

https://www.sciencefocusngr.org

[16] Fraser, D.C. (1969) Contouring of VLF-EM Data. Geophysics, 34, 958-967. https://doi.org/10.1190/1.1440065

[17] Oladunjoye, M., Adabanija, M. and Adeboye, O. (2013) Groundwater Prospecting 
and Exploration in a Low Potential Hard Rock Aquifer: Case Study from Ogbomoso North, South-Western Nigeria. Journal of Environmental and Earth Science, 3, 84-102.

[18] Adiat, K.A.N., Adelusi, A.O. and Ayuk, M.A. (2009) Relevance of Geophysics in Road Failures Investigation in a Typical Basement Complex of Southwestern Nigeria. Department of Applied Geophysics, Federal University of Technology, Akure, Nigeria, 704. 